Final version:

Dobele, A. and Lindgreen, A. (2011), "Exploring the nature of value in the word-ofmouth referral equation for health care", Journal of Marketing Management, Vol. 27, No. 3/4, pp. 269-290. (ISSN 0267-257X)

For full article, please contact LindgreenA@cardiff.ac.uk

\title{
Exploring the Nature of Value in the Word-of-Mouth Referral Equation for Health Care
}

\author{
Angela Dobele, ${ }^{1}$ RMIT University \\ Adam Lindgreen, University of Birmingham
}

\begin{abstract}
Understanding the nature of customer value in health care is critical given the diversity of consumer needs, an increase in the number of providers, and resource pressures faced by private and public providers. A move to greater accountability and consumer sensitivity also has driven this need, especially since many providers of healthcare funds incorporate customer satisfaction into performance measures. To understand consumer value in healthcare we focused on one context—word of mouth referrals by new mothers. Drawing upon 16 in-depth interviews, we identify the nature of value discussed including the quality of the experience, staff friendliness and expertise, and source credibility.
\end{abstract}

Keywords: value, word-of-mouth referrals, healthcare, interpretive research.

\footnotetext{
${ }^{1}$ Email: angela.dobele@ rmit.edu.au.
} 
Acknowledgements: The authors thank the two anonymous reviewers, Lisa Farrell and Tim Fry for their constructive feedback on earlier drafts. 


\section{INTRODUCTION}

Understanding and creating customer value is fundamental to marketing activities (Holbrook, 1994; Lindgreen \& Wynstra, 2005). Yet the concept of value is 'multifaceted and complicated and there is an evident risk that the concept is used without any efforts or commitments to understand ... what it means', such that 'the achievement of profitability for the parties involved' may suffer (Ravald \& Grönroos, 1996, p. 19). Despite these difficulties, the effective provision of value represents one of the most successful strategies a company can adopt to develop a sustainable competitive advantage (Heskett, Jones, Loveman, Sasser, \& Schlesinger, 1994; Quinn, Doorley, \& Paquette, 1990; Treacy \& Wiersema, 1993).

While, the measurement of this construct appears simple, the difference between benefits minus costs, there are three main impediments make evaluating value difficult though. Value is contextually bound and subjectively experienced (Vargo \& Lusch, 2008), thus each person applies their own meanings and interpretations to their experiences; it may offer both extrinsic and intrinsic benefits (Batra \& Ahtola, 1991; Mano \& Oliver, 1993), for example, it brings a physical reward and an intangible reward judged by the person, which can differ greatly between individuals; and it comprises multiple, inter-dependent or independent dimensions (Sheth, Newman, \& Gross, 1991; Sweeney \& Soutar, 2001) such as the past experiences of the individual, their own beliefs and emotions, their relationships with others and the beliefs and experiences of those others all play a role in judging the concept of value and add to the inherent difficulty of applying a single definition to the construct.

This article investigates the role that value plays when female patients with children refer health care professionals and/or organisations to other mothers. This focus on mothers provides a compelling framework for investigating value within the health care industry, in that they gain exposure to the health care industry on their own behalf (e.g., pre-conception, conception, pregnancy and delivery) and as the mother of a patient (e.g., paediatric general health checks, specific health issues). Thus, mothers play primary roles in making health care decisions on behalf of themselves and their dependent family members. Furthermore referrals are important in the health care 
industry, but current understanding is limited with regard to the specific aspects of health care services that customers value. The term 'referral' as used herein describes informal communications between mothers, rather than a professional referral by a general doctor to a specialist, which matches the usage in existing marketing literature.

Previous research on marketing in the health care industry has focussed mainly on management issues or the organisation, rather than patients. Research into word-ofmouth in this industry also notes its importance but has not uncovered how patients value these referrals. Therefore, this study offers new insights into measures of the value of word-of-mouth referrals from mothers. Its practical implications relate to the marketing strategies that such knowledge may elicit, for use by health care providers.

\section{VALUE AND HEALTHCARE}

Value in the health care industry is complicated by three features. First, the high level of information asymmetry between the buyer (patient) and seller (health care provider) means the buyer must trust the supplier to ensure its efficacy, pricing and product design are well matched to his or her needs; therefore, the seller is essential to value creation for the buyer. A patient must have some level of trust in the health professional, which implies the buyer must be highly involved in the delivery process, despite low expertise (Taner \& Antony, 2006). Due to the high information asymmetry, the health care professional determines the services that will suit the patient's requirements (Mattila \& Wirtz, 2002). Second, consumers do not seek health care services for the service itself but rather as a means to achieve good health, which sometimes requires them to use a health care provider to aid that process (Evans, 1984). Third, there is usually a high degree of risk associated with the very nature of the service (Taner \& Antony, 2006), which suggests high consumer involvement (Hogg, Laing, \& Newholm, 2004), combined with a high degree of emotional vulnerability and exposure (Jadad, 1998).

For health care providers, the need to consider customers has become increasingly important as a result of greater competition and medical reforms. For example, more private hospitals means that companies must develop new methods to maintain their customer bases and increase new customer numbers (Ekrem \& Fazil, 2007). 
Traditionally, the health care industry has had difficulties creating meaningful value through innovation, due to the structure of health care financing, the lack of vertical and horizontal integration and the slow translation of basic research into meaningful health outcomes for the broader population (Duncan \& Breslin, 2009).

Health care organisations that can overcome these difficulties gain an advantage over competitors by offering high value care (Duncan \& Breslin, 2009). Understanding how and why consumers purchase such professional services may be the key to such a unique competitive advantage. Because of the increasing importance of creating patient satisfaction through value-enhancement strategies (Richardson \& Gurtner, 1999), contemporary marketing plans for the health care providers are predicated on the notion of creating value for patients (Beresford \& Branfield, 2006; Nordgren, 2009). However, when selling credence goods, such as health care, suppliers also must consider value from the customer's perspective; many professional firms fail to do so and thus offer inferior value to customers (e.g., de Brentani \& Ragot, 1996).

Hospital management practices aimed at incorporating quality, customer satisfaction and loyalty have evolved, as evidenced by their attempts to influence customer perceived value (Ekrem \& Fazil, 2007) by involving patients centrally in value creation (Duncan \& Breslin, 2009). However, despite this shift toward a more patientcentred culture (Laing \& Hogg, 2002), patients still tend to be regarded as passive recipients of care (Ham \& Alberti, 2002). This sense of passivity may stem from a traditional 'doctor knows best' belief, which granted power primarily to medical professionals who took a domineering approach (Laing \& Hogg, 2002), while the patient deferred to the professional's opinion and obeyed instructions that the professional deemed best for patients' health (Neuberger, 2000). Alternatively, patients themselves may be unwilling to express consumer expectations and behaviour with respect to health care (Laing \& Hogg, 2002).

The culture of the health care industry may be changing from a traditional model of transactional or commercial activities toward a more outcome- and performancebased orientation, built on a network and partnership approach (Beresford \& Branfield, 2006) and involving a shift in responsibility from the medical professional to the patient (Lo, 2006). Yet it is a slow process, made more difficult by the nature of 
value. In addition to the complexity of the value concept, the intangibility of the service provision, the high level of information asymmetry and the derived demand for a health care treatment, the health of a child may be involved, in which case a parent would feel additional decision pressure.

\section{Word-of-Mouth and Value}

The decline of restrictive forms of managed care and rapid increases in the availability of health care information via the Internet may produce a situation in which consumer-provided information is more highly valued by recipients during their information searches and selection (Herzlinger, 1997; Robinson, 2001). Thus, word-of-mouth communications or referrals have significant importance for the health care system, both traditionally as a means to cut through information asymmetry and more recently as a tool for health care providers to gain understanding about what patients actually value.

Research confirms the importance of word-of-mouth ("an exchange of thoughts, ideas, or comments between two or more consumers, none of whom is a marketing source" (Bone, 1992, p. 579)) in the health care industry (Fisher \& Anderson, 1990; Gombeski, Carroll, \& Lester, 1990; Murray, 1992; Williams \& Hensel, 1991). Patient word-of-mouth in particular is becoming increasingly important for hospitals and treatment providers, because patients 'can play an important role in achieving optimal health by taking an active and informed role in treatment decisions and switching physicians if care is unsatisfactory' (Harris, 2003, p. 711). Consumers use word-ofmouth referrals for reassurance or confirmation that they are making the right decision, such as 'What do you think of that doctor?', or to sort through multiple alternatives, such as 'Which birthing hospital do you think is best?' (Bikhchandani, Hirshleifer, \& Welch, 1991). Referrals provide information that can reduce uncertainty (Belkin, 1978; Buckland, 1991; Dervin, 1990), which should be important for a high-risk decision such as health care. The provider's intention to offer positive word-of-mouth communications correlates positively with customer perceptions of value and quality (Derbaix \& Vanhamme, 2003).

When considering the range of professionals involved in a mother's health care, the list can be daunting. There are health care professionals who advise on parents' 
attempts to conceive. During pregnancy there are general practitioners, dietary advisers and ultrasound operators. During the birth, hospital and medical staff (e.g., anaesthetist, general practitioner and paediatrician) and specialist staff are on hand for any complications that may arise. With a new baby, the list of health care professionals expands to include general practitioners, paediatricians, obstetricians and other health care staff. If the babies or pregnant mothers suffer health problems, the range of health care professionals may be extended to include specific professionals (e.g., diabetes specialists) and support staff related to those health problems (e.g., blood testing, dieticians). Finally, beyond hospitals and treatment centres, mothers must choose health centres for their newborn babies' regular health checks during their first eight weeks and treatment and product intermediaries (e.g., pharmacies) and insurers. Thus, a mother confronts a vast number of health care providers and must sort through the array of alternatives on behalf of both herself and her children. To ease this difficult decision process, patients might not engage in rational information searches to select physicians but instead rely on recommendations from family and friends, which constitutes a limited search for alternative physicians (Hoerger \& Howard 1995; Lupton, Donaldson, \& Lloyd 1991).

\section{METHODOLOGY}

Since we explore the experiences of mothers during their information searches and knowledge exchanges when sourcing and discussing health care providers, we adopted an interpretive approach. The lack of clarity surrounding the concept of value, the importance of referrals for value chains and the complexity of such questions also support the use of a qualitative research approach. Specifically, the research question centres on the role of value when mothers recommend health care professionals or services to other mothers. Mothers' views of value appear in what they talked about and with whom. That is, experiences can be analysed in terms of the referrals sought from other mothers, professional health organisations or professionals or electronic sources such as websites or blogs.

The sample consists of mothers predominantly located in Australia, Belgium and the United Kingdom, three countries with different health care systems, which should provide sufficient heterogeneity to allow for comparisons. The analysis and discussion of results with the informants confirm fairly similar health care stories 
within the respective countries. Although the systems of private and public health care may differ across the three countries, this research focuses on referrals offered by mothers, rather than on a comparison of health care industries.

Data collection involved a combination of e-mail surveys and in-person interviews, conducted in the home of the mother. The informants received the interview questions via e-mail when they agreed to participate, as well as follow-up questions after each interview if necessary. The interviews included nine women who had recently become mothers and seven who have been mothers for at least three years, including one new grandmother with adult children (see Table 1 for details). The opening question defined the nature of the topic without implying any response constraints (Dick, 1990): 'Please think about a referral you gave for a health care provider you have experienced. Please tell me about it'. In effect, this carefully designed question encouraged informants to speak about their own factual experiences with the topic of interest, which then led to more specific areas of inquiry.

Because the research focus is on the substance of the communication and any critical incidents that may have led to such communication, the authors performed thematic analyses independently, then compared their interpretations and resolved any disagreements through discussion. The overall analysis continually tacked back and forward between literature on value and word-of-mouth referrals and the data (dialectical tacking); the result was several theoretical categories and sub-categories that include both descriptive and interpretive explanations of the data (Spiggle, 1994). After second interviews with each informant, the authors compared their summary notes from the discussion with their prior notes to identify common themes. The analyses after each interview relied on open coding (grounded theory techniques) to identify the sub-value dimensions (first-order codes) and the referral value dimensions to which they pertained (second-order codes) (Strauss \& Corbin, 1998). Informants were asked to remember as much detail as possible about the referrals they had given and received.

\section{Table 1. Informant Details}

\begin{tabular}{|c|c|c|c|}
\hline Participant* & $\begin{array}{l}\text { Age Group, } \\
\text { Years }\end{array}$ & $\begin{array}{l}\text { Country where Mother is } \\
\text { currently located }\end{array}$ & Age and Gender of Children \\
\hline
\end{tabular}




\begin{tabular}{|c|c|c|c|}
\hline Jennifer & $36-44$ & Australia & 8 years, female \\
\hline Diana & $36-44$ & Australia & 22 months, male \\
\hline Sophie & $45-54$ & Australia & $\begin{array}{l}17 \text { years, male } \\
14 \text { years, male } \\
13 \text { years, female } \\
12 \text { years, male }\end{array}$ \\
\hline Natalie & $36-44$ & Australia & 22 years, female \\
\hline Samantha & $55-64$ & Australia & $\begin{array}{l}36 \text { years, female } \\
29 \text { years, male } \\
\text { Grandson, } 14 \text { months }\end{array}$ \\
\hline Megan & $36-44$ & Australia & 3 years, female \\
\hline Joanna & $45-54$ & Australia & $\begin{array}{l}26 \text { years, male } \\
24 \text { years, male } \\
20 \text { years, male }\end{array}$ \\
\hline Ella & $45-54$ & Australia & $\begin{array}{l}24 \text { years, male } \\
21 \text { years, male }\end{array}$ \\
\hline Clare & $36-44$ & Australia & 11 years, female \\
\hline Deborah & $26-35$ & United Kingdom & 13 months, female \\
\hline Christine & $36-44$ & United Kingdom & $\begin{array}{l}5 \text { years, female } \\
1 \text { years, male }\end{array}$ \\
\hline Kathleen & $36-44$ & Belgium & $\begin{array}{l}3 \text { years, female } \\
4 \text { months, male }\end{array}$ \\
\hline Emma & $26-35$ & United Kingdom & 14 months, female \\
\hline Janice & $36-44$ & Belgium & $\begin{array}{l}2 \text { years, female } \\
\text { Pregnant with female baby at time } \\
\text { of interview }\end{array}$ \\
\hline Stacey & $26-35$ & Belgium & 8 months, male \\
\hline Erin & $36-44$ & United Kingdom & $\begin{array}{l}7 \text { years, male } \\
2 \text { years, male } \\
2 \text { years, female }\end{array}$ \\
\hline
\end{tabular}

* Pseudonyms.

\section{FINDINGS}

The findings revealed two clusters of referral value: the credibility of referrals and the referral content (see Figure 1); this figure also depicts the dimensions making up the two clusters. Mothers also noted the overall importance of referral sources as impartial information resources.

Referral sources offered information about health care options available within certain communities or social networks. The mothers in our study believed that word-ofmouth communication among mothers was very important, because as Clare described it, 'word-of-mouth about your child's health is such an important issue'. 
Referrals served as a means of obtaining and judging information about a range of health care providers:

Mothers listen and talk about good and bad experiences.... If I hear someone with a negative or positive comment it does get stored away for later. Mums are looking for the best child care ... best GP. And we talk a lot.... We talk about doctors and local child care nurses. We talk about who gives good versus average care, or shite care. You ask 'Who seemed interested in your child? Who listened to you, to your child?' because you want the best (Megan).

Word-of-mouth communications are most important in seeking a recommendation for a health care provider; once you visit you can do your own assessment. But, I think personal recommendations-not from those in the industry! - are extremely important at that beginning stage, they save a lot of time, something mothers have in short supply (Jennifer).

As these passages reveal, mothers placed great importance on referrals when selecting health care providers for their children. They not only wanted to achieve the 'best' level of care for their child, but also needed to save time by shortening the information search and decision-making processes.

\section{Figure 1. Dimensions of referral value in health care industry}

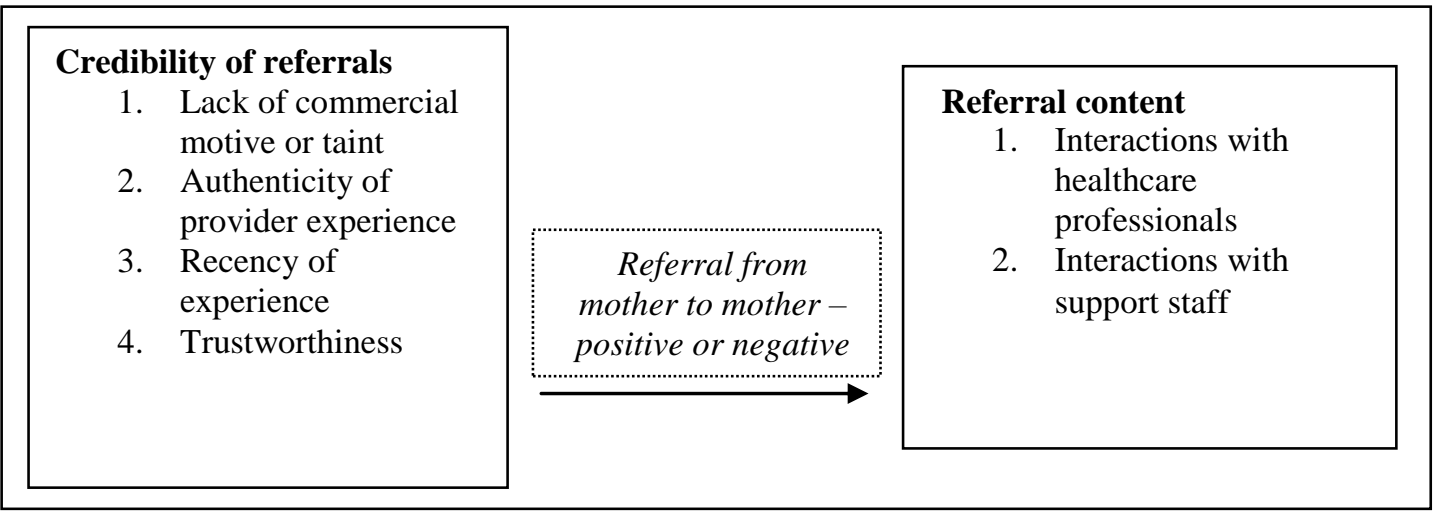

\section{Credibility of referrals}

\section{Recommendations from friends and family}

Implied in Jennifer's quotation is trust or belief in a personal recommendation rather than paid marketing communications from a health care provider or referral from a paid employee in the health care industry. Jennifer believed that personal recommendations offered more credibility than paid marketing messages or referrals 
from health care professionals. Prior research similarly has shown that personal referrals and information produce higher perceptions of credibility or believability (Fogg, 1999), as well as being trustworthy or having expertise (Self, 1996). A referral source could be judged as credible according to its perceived competence, character, composure, dynamism or sociability (Burgoon, Bonito, Bengtsson, Cederberg, Lundeberg \& Allspach, 2000). Tseng and Fogg (1999) identify four types of source credibility: (a) presumed credibility, built on assumptions or stereotypes, such as not trusting used car salespeople or trusting movie stars; (b) reputed credibility, which is based on source labels such as the trust people have in doctors; (c) surface credibility or judgements based on the look of something, like judging a book by its cover; and (d) experienced credibility, which is achieved by first-hand experience with a source over time. The latter form is the most complex and reliable for making credibility judgments (Tseng \& Fogg, 1999).

Comments by Deborah, Samantha and Diana all implied this latter form was the most important:

I looked for recommendations for where to have my baby [choice of hospital] but found that those giving the advice, my GP and the Health Visitor, were very biased towards one option. No healthcare professional seemed to give me a balanced view or a full list of pros and cons for me to then base my decision on. The most useful advice I had was from friends who had had children already (Deborah).

I believe [referrals from other mothers] is the most reliable because the person giving the recommendation does not receive any monetary rewards for giving the information (Samantha).

The referrals I received from my friends were given more weight than those from the professionals because of the self promotion aspect (Diana).

Thus, these mothers exhibited a preference for a referral from a personal source rather than an employee of the health care industry. They also judged such referrals as more valuable than marketing communications from medical organisations, largely because of the lack of a financial reward to the source for offering these referrals. The lack (or perceived lack) of financial rewards appeared to enhance the credibility of the referral 
source. Some mothers expressly noted the lack of monetary or financial rewards as a reason to trust the referrals they received:

I personally went by this information I believe it is the most reliable because the person giving the recommendation does not receive any monetary reward for giving the information (Samantha).

Natalie similarly valued referrals from family, friends and work colleagues but expressed her preference as based on the impartiality of the referrals due to their lack of formal ties with the provider. That is, she believed her referral sources 'aren't getting any kickbacks for making the recommendation'. If she 'knew that someone who recommended a service was getting a monetary reward', she 'would think less of the recommendation'.

\section{Recommendations from business and their employees}

From a business perspective, some companies encourage their employees to undertake referral generation behaviour, such as by creating and maintaining professional but individual relationships or inter-personal bonds with other staff and clients (Gremler, Gwinner, \& Brown, 2001). In the health care industry, these referrals may provide a secondary source of information, but our informants seemed unlikely to trust those sources of information if other sources, unaffiliated with the industry, were available. None of our informants had ever been rewarded by a health care provider for their referrals. Rewards might have included tangible offers, but no mother in our study had even been thanked for past referrals. This lack was an issue for Diana; at the very least, she believed she should have been thanked for the referrals she has offered:

It is professional courtesy to at least thank the person for the referrals, even if it is an email just to let them know if the person took up the product/service recommended (Diana).

Sophie was more forgiving and offered a possible explanation for the lack of appreciation for referrals:

...most doctors and dentists cannot even tell you that they saw someone without being worried by privacy legislation (Sophie). 
Despite her rationale though, Sophie, along with Diana and Natalie, would welcome a thank you or some form of recognition for referrals:

Dentists' bills are so huge that perhaps some kickback from introducing new customers would be great! (Sophie).

A thank you and maybe a gift, or if done often and you receive great value then pay a referral fee (Diana).

I would like some verbal appreciation of acknowledgement but it doesn't have to be a monetary reward. [Why not a monetary reward? (Interviewer)]. My referral would lose value (Natalie).

Overall, our informants were not looking specifically for financial rewards but preferred, as Jennifer stated, knowledge that their referral has actually helped another mother find a competent health care provider for her child:

Given that the services are not always relevant to everyone, I only mention a specific provider if someone is actually looking for that type of service. That way I know what I say will actually help (Jennifer).

I relied on word-of-mouth so much when I was first married. I am happy to help anyone who needs it, I guess it's a way of paying forward (Samantha).

\section{Trusted sources: motherhood experiences}

Thus, the mothers in our study placed a high value on referrals they received from trusted sources. These trusted sources did not include marketing communications from health care providers. For example:

I think personal recommendations between mothers are very effective. It may take a few changes and recommendations before you find the professional or service you are happy with but I would always start with a personal recommendation rather than an advertisement in a magazine or paper. Recommendations are very important. When choosing someone to take my children to I would only see someone who had been recommended (Christine).

These quotations demonstrate that mothers' preferences were for referrals they received from trusted sources, which they judged as more valuable than other information sources. This trust was based on a perception of neutrality; the referral sources were not paid, were not employed in the industry and did not receive benefits 
from passing on their recommendations. Mothers also used three main measures to define or judge the referral source's trustworthiness: experience, recency of motherhood and relationship with the source provider.

Two quotations specifically showed the value that mothers placed on actual experiences of with motherhood and care for a child:

Experiences from other people are worth their weight in gold (Sophie).

'Mothers ... should make sure they join a mother's group to share ideas and problems. Experience is always the best kind of advice.... Personal recommendations play a very important role. Nothing beats experience. A text book cannot cover all scenarios (Joanna).

Sophie preferred first-hand accounts of other mothers' experiences, and Joanna rated others' experiences as more trustworthy than information she could find in books. The length of the referral source's motherhood also played a role in the determination of believability and source credibility. The more recently a mother had given birth and thus experienced the health care provider's service were taken into consideration:

The value level I place on [referrals] depends on the source it comes from. The value from some family members or friends may be greater than others, for example, a friend who has just had a baby in the last three years is valued above my mother or mother-in-law (Diana).

Thus, the informants might listen to referrals offered by mothers of older children, but they placed greater weight on referrals from new or more recent mothers. Experience was not always determined by the length of time a mother had been a mother though, in that one informant considered the sources of information used by those who referred her to various health care providers:

I do tend to place more reliance on recommendations from people that I consider to be knowledgeable. For example, I frequently ignored medical suggestions from a member of the extended family due to her habit of using Women's Day, New Idea and Reader's Digest as authoritative medical sources (Ella). 
Experience as a means of judging source credibility was further exemplified by Emma, who sometimes discounted referrals offered to her by colleagues who did not have children:

I place a higher value on recommendations from my friends who have had babies ... the value I'd place on recommendations from work colleagues and professionals in the industry would depend on my personal opinion and experience of the individual giving the recommendations (Emma).

Thus, the mothers valued referral sources for their provision of two benefits. First, a trusted referral, which can be acted upon, saves the busy mother a potentially long information search. Second, it may help her to feel more confident about her choice of a health care provider as the best one in terms of ensuring the best care for her child. Personal referrals offered more value than the paid communications of health care professionals, as well as compared with referrals from employees or professionals in the health care industry.

\section{Characteristics of referral judgments}

The overall level of trust used to judge a referral depends on three main characteristics. First, the mother needed to perceive the referral source as independent, which meant they were not paid for their referral, were not employed in the industry and did not receive other benefits for passing on their recommendations. Second, the referral was trusted if it reflected some level of experience with the service, such as a source who had given birth in the particular hospital she was referring to a pregnant woman. Third, the mothers judged the experience and knowledge of the referral sources. For example, a mother whose experiences were more recent seemed more trustworthy than a mother with adult children.

These findings also related to the referrals that the mothers in our study sought. That is, when we asked about referrals they have given to others, a similar pattern of judgements emerged. They again mentioned trustworthiness in terms of their perceived impartiality compared with that of commercial messages, such as:

I offered the recommendation voluntarily. I suppose my thinking behind this was the fact that the only advice [mothers received] was from health care 
professionals themselves, whom I believed were biased towards their own organisations (Deborah).

I get asked a lot about who I see and who I take [child's name] to, who I prefer. I offer recommendations about styles and level of care. [Child's name] and I have been through a lot together [laughs], I guess that's why I get asked for recommendations all the time (Megan).

However, these sources of information did not ignore or discount information they received from other sources but rather used them in conjunction with trusted referrals sources:

Friends are of course a valuable source of information ... but probably not to solve a real medical problem ... maybe just to confirm what to do. ['Do the referrals help you to make a decision?' (Interviewer).] Yes, you get multiple opinions and then decide. I listen to the doctor but I also ask around. But it would depend on the situation. A serious medical problem I would definitely just listen to the doctor. For something like diet and nutrition, and development stuff I got opinions from my mother's group (Kathleen).

Never dismiss the medical profession. I always try them first. If I get no satisfaction I find other ways either by asking people or looking through the Internet (Joanna).

As Joanna suggested, the Internet is a good secondary source of information that helped the mothers reduce post-purchase dissonance and saved them time by avoiding continued information searches or decision-making process. It was not available for some of the older mothers in the sample, but this tool now provides a common resource to confirm an existing purchase choice or decision. For example:

Internet sources are good to go to for additional information but not as a final word (Megan).

Yet the majority of the informants indicated they accessed Internet sources in the past but no longer used the resource, because of their perceptions of a lack of believability and bad prior experiences:

I have never found any relevant recommendations on local health care services in the Internet (Emma). 
I do not use Web sites very much — anyone can write anything (Clare).

One or two times I also searched the Internet for help; but I quickly stopped using this source of information as there are a lot of horror stories which you do not want to read about (Kathleen).

Informants also mentioned the importance of the information they were seeking or providing to others, because it applied to their children. The referral source therefore was very important, in that they expected to use that information to provide health care services for their children.

\section{Referral content}

When judging a service, customers generally evaluate their perceptions of the service quality using attributes such as communication, competence, reliability and responsiveness as indicators of trust, satisfaction and commitment (Brady \& Cronin, 2001). Patient satisfaction in particular depends on a patient's interpretation of the health care interaction (Janz \& Becker, 1984), including the bond that develops between a doctor and patient (Hausman, 2004). When the experiences are positive and a positive emotional bond develops, the patient likely evaluates the service positively (Coulehan et al., 2001).

In turn, the search for medical practitioners who could offer positive encounters with their children was important for the informants. Mothers considered the type of service their child would receive from a new medical practitioner and provided information to other mothers about this important characteristic:

You know your child's personality and do not want your child to get upset because of a bad mannered dentist, for example, who gives them a fear of dentists for the rest of their lives (Sophie).

\section{Health care professionals}

To aid in the decision-making process, mothers used measures of personal service they had experienced, such as the personality of the health care professional or administrator, as touchstones for judging the various services and providers available to them, on behalf of their child. The ability of a medical organisation to create positive service experiences also influenced the search for medical practitioners: 
We often discuss the [hospital] with colleagues and friends because of a somewhat confusing reputation, some people love this hospital (because of very good experiences, like me with the friendliness of nurses and doctors as well as the perceived quality of care), some others not at all (because of very bad experiences like the death of a baby in that hospital because of perceived lack of care). I am always saying that it is difficult to recommend a hospital because, depending on the circumstances, you could be really happy afterwards or not at all and I do not like to feel responsible for others so important life experiences. Furthermore, the quality of a hospital is really dependent on the service considered. For instance, I would recommend the maternity ward in [hospital name] but not at all the paediatric service!! ['Why not the paediatric service?' (Interviewer).] The staff there are awful! Always rude and in a rush. I felt like they were not listening to me, or my daughter. They were not there for us. ['Is 'being there for you" important to you?' (Interviewer).] Yes. I recommend ... my specialist to a lot of people because I find her very friendly, competent and available for her patients. I think that is important (Janice).

Thus, for Janice, the bond among her daughter's paediatric service professionals, her daughter and herself was important. She wanted professionals who would 'be there' for her and her daughter. The maternity ward and the paediatrics division were in the same hospital, but the services she experienced were very different, so Janice sought an alternative paediatrics unit after her negative service experience.

The relationship with a paediatric service may last until the child reaches adulthood. Therefore, a defining criterion pertained to the length of time the service would likely be needed, which served as a measure of attachment to that service. Poor or negative experiences with a birthing hospital may encourage a mother to seek an alternative birthing hospital for her next child, but not during her recovery from the current birth, because the time she has to put up with poor service is limited. However, a poor paediatric service provider cannot be tolerated due to the length of time that service is required, which led Janice to seek a different service provider. This finding adds to current understanding about the use of referrals to aid purchase decisions for seemingly high-risk products and services (e.g., Ennew, Banerjee, \& Li, 2000). 
The bond among the service provider, mother and child also was important for Emma, who had issues with her local health care centre in which more than one medical doctor works in rotation. Unless a mother requests a specific doctor when making an appointment, they receive the first available doctor. Emma had several negative service experiences with some doctors and therefore began 'warning' other mothers of this experience:

I have ... warned friends with babies the same age as me who also live near me (whilst chatting over lunch at a local pub) about certain doctors at my local GPs who I have had negative experiences with. ['What happened?' (Interviewer).] One included a doctor who called my baby a 'spoilt little brat' when she was very tiny and also failed to offer me an examination at my 6 week check. Another criticised me for asking for the contraceptive pill whilst breast feeding saying it was unnecessary. ['What did you do?' (Interviewer).] I went to another doctor. Much better doctor. I (now) recommend this doctor who has been very supportive with some problems I have had since my baby was born. ['Is “support” important to you?' (Interviewer).] Yes. My new doctor was much more supportive of me and my baby. I felt, comfortable. I could ask my questions and get help and answers (Emma).

Again, the creation of a bond between the service provider and patient, whether mother or child, was important for the mother. Other informants confirmed the importance of bond creation:

I give a description of the manner first. You have to be careful, for example, I won't recommend a particular [health] provider to boisterous people, only quiet ones. They just wouldn't suit! I try and recommend by manner if ability is not the issue. ['What do you mean by 'manner'?' (Interviewer).] I asked my sister for a recommendation for an $\mathrm{O}$ and $\mathrm{G}$ specialist [i.e., obstetrician and gynaecologist, a medical practitioner who specialises in childbirth] ... she thought for a while and then recommended someone to me. She thought his personality would suit me. She said he was a straight talker but a funny man. ["And a "straight talking funny man" was something you thought important? (Interviewer).] (Laughs) Yes! It was important to me as you have to laugh; you have no dignity left when you have a baby (Sophie). 
I give feedback as to my experiences with them or the experience of others I know who have used them (Diana).

I recommended my obstetrician to others-I can't remember specifically what I said but it was in relation to his bedside manner and interpersonal skills, and the fact that he was quite caring (Clare).

I always give the names of people who offer a good service. Getting a good service is important (Samantha).

The informants thus appeared to be judging the people skills of their health care professionals, rather than their level of training or professional qualifications. This focus could be because inexperienced laypeople find it difficult to judge professional qualifications (Toweill \& Christopher, 2005). Using their own direct experience of the service received from a medical practitioner, whether directly or on behalf of their children, the mothers offered referrals that mentioned those skills they could evaluate. In service industries, the range of offerings is largely intangible, so the reputation or manner of a particular medical practitioner may provide a criterion to judge the service and provide cues for patients making a purchase decision (cf. Fombrun, 1996). The mothers in this study searched for attributes they could judge or would feel comfortable judging. As a result, a mother who experienced the service provider's treatment of her child or herself and offered a recommendation (i.e., use or avoid the provider) based on that experience represented a valuable source of information who could be trusted and believed.

\section{Support staff}

Referrals from informants also referred to the support staff, not just the health care professional. Mothers' comments extended to include those involved in the overall provision of a particular service, such as administration staff:

I've given negative feedback to my mother's group about the first obstetrician I was seeing. It was not the doctor that put me off, it was his receptionist. I've discussed this person with my mothers' group and everyone agreed that they disliked her and wished they did not have to deal with her as they like the doctor (Megan). 
In this example, Megan did not form a positive bond with the receptionist at her particular health care centre. The receptionist even had become well known for her rudeness in Megan's mother's group, which warned new mothers to expect such behaviour when dealing with this particular receptionist. Megan continued to visit this health care centre, because the bond she had formed with her doctor and the associated benefits outweighed the negative service experiences with the receptionist. This scenario reveals that mothers may experience a negative service encounter but continue to see the specialist - and even recommend that health care professional. In consulting with a paediatric gastrologist for her daughter, Megan explained,

Although I was not a fan of his approach, I was advised by a number of people to stick with him as he is very good at his job. My daughter was ill and this particular doctor had a reputation amongst my mothers' group for being good at his job. This actually happens a lot, where medical people have no bedside manner but are geniuses in their field. ['So why do mothers stay with someone who is giving such poor service? Was there no other doctor who could help your daughter?' (Interviewer).] I think there is such a demand for many services these days that many doctors don't really feel they have to worry about bedside manner and patient treatment. It's the same with hospitals. When you have a baby in a private hospital, like the one I was at, they actually have a person employed there to hurry you along, to get you out as quick as possible. With so many in the line behind you many doctors feel if you walk that there are plenty that will take your place. In this case, while I thought about getting another paediatric gastrologist for my daughter, he did have a good reputation for sorting out this type of problem, just not a good reputation for his bedside manner. And he helped my daughter and we have not had to see him again. ['Would it have been different if the problem was more long-term or required several repeat visits to that particular doctor?' (Interviewer).] Definitely! I would have looked for another doctor. But I could put up with him in the shortterm, especially because all the advice I was getting said he was good at his job. Just not good with kids. Or (laughs) perhaps just not good with demanding mothers!' (Megan).

Megan made another interesting point in this quote about being 'a demanding mother'. This descriptor was not immediately evident in her interview; she seemed an 
articulate and highly educated woman who visibly put the health of her child before her own. In both experiences she recounted, she experienced poor service from a receptionist and a medical practitioner and made changes where appropriate. Upon further probing of her actions in these situations, she noted,

I have had to see a variety of specialists, both for me and for [daughter's name]. Some of the receptionists have been quite rude or sharp. When it's you, as an adult, you feel quite confident to say 'no, I don't think I will be treated that way' and you will do something about that, right then and there. But when you've got a sick child and you are desperate to get in to see a doctor you are more willing to put up with a rude receptionist because you won't risk that receptionist making your life difficult and holding up your child getting help. ['So you let it end there?' (Interviewer).] No way! I will take it up with the doctor after my daughter has been seen; you want to nip that one in the bud. I will tell them that 'I've watched the receptionist being rude to five different people and that they are costing you business. She is rude and abrupt, she treats the old people like morons and everyone else with contempt.' Medical staff are more important but when you've got a child you want someone who cares about service. She [the receptionist] doesn't have to hug me, or kiss my child or anything like that, but I want them to have the nurse to think maybe I should put this call through or get a doctor to call me. You want a receptionist that if there is drama you want to get in to see them right away, when you've got a child. I expect a 'hi' or some acknowledgement sure, but what is really important is how they react to an emergency. Some of them will just point blank say "no the appointment book is full' because that's creating extra work for them (Megan).

Megan's comments clearly showed the importance of good service from the support staff involved in medical treatment. But her negative service experiences also included medical staff, such as the gastrologist for her daughter. Megan posited that the problem may be more common among older or more 'traditional' medical practitioners:

Most older doctors have this attitude that says 'I'm a doctor, everything I say is correct and I don't have to do anything else except be a doctor'. But the doctor should be personable, they should talk to the child ... some of the doctors I've taken my daughter to don't even acknowledge her. She's nearly four, at this age 
she needs to be acknowledged. The doctor should be thinking to themself 'hey I'll win you over before I poke and prod you' and these are the doctors who will talk to [daughter's name], engage with her, make her smile. But they think 'I'm a doctor so I don't have to do that'. Stupid, because the more [daughter's name] gets that kind of treatment ... the more difficult she is to examine. The doctor makes it harder for themselves, for me and for [daughter's name] (Megan).

Clare also had negative service experiences with both medical and support staff. In turn, she suggested that just providing a positive service experience would be enough to satisfy her and prompt her to offer positive word-of-mouth referrals:

Give me something to recommend!!... [I] have had so many bad experiences, that just getting reasonable service means I am likely to recommend [them] to others (Clare).

The informants made frequent judgements about the health care professionals and support staff they encountered when seeking treatment for their children. Mothers judged service quality on the basis of their personal interactions with the health care provider, such as doctors, nurses or pharmacists, and the support staff, including receptionists.

These personal interactions, beyond just the supply of medical assistance, were important to these mothers. Personal interactions that benefit both parties can lead to relationship marketing, particularly in service industries in which the person who manages the relationships is likely responsible for their success or failure. To develop customer loyalty, especially in an increasingly competitive industry such as health care, the service organisation can develop a system that prompts favourable client responses and continued service choices.

\section{Physical evidence}

Although most of the mothers did not place a high level of importance on physical evidence (beyond noting it was a hygiene factor - no pun intended), this changed if encounters with health providers were lengthy. For example:

If I had to give it a score out of 10, physical surroundings are a 2. You don't want to take your child to a rat-infested or filthy place, but everywhere I have 
ever been has always been clean. Most paediatric centres are set up in hospitals so you expect them to be cleaned to a hospital standard. ['The surroundings just don't seem to be that important?' (Interviewer).] Doctors should realise that it makes life a whole lot easier and calmer for everybody if the waiting area and consultation rooms are set up with children in mind ... where I take my daughter for her regular check-ups has a spaceship and a big fish tank set up in the middle of the reception area. Around the outside of the area are lots of toys and books and bright pictures. As a parent it's easier to take your child in to an area like that than an area that has jack. Most of the places we've been to have at least a minimum of stuff, I think most doctors realise that keeping the children occupied makes it easier for everybody (Megan).

Despite an emphasis on physical evidence or atmospherics in other service contexts, mothers primarily interpret the physical features in a clinical way-the understandable focus on cleanliness and sterility. As well, Megan's emphasis on surroundings as a means to reduce tension and stress suggest that this is a hygiene factor. As such, descriptions of surroundings are likely to be part of word of mouth only if minimum standards of cleanliness are absent.

\section{DISCUSSION}

Two key themes emerged from this research. First, informants valued referrals as a means to confirm information, understand options and reduce information search anxiety and time. The referrals offered important tools or resources, especially if the advice came from a trusted source. Evidence of believability existed when the referrer was thought to be unpaid, offered the referral voluntarily and provided referral content based on recent experience and/or knowledge (whether personal or from a trusted third party). Second, the referrals focused on tangible characteristics of service providers, such as bedside manner or skills in handling children, as well as the tangible characteristics of support staff, such as the politeness of receptionists. Informants looked for discernable aspects of the service to judge the value of a referral. If the medical practitioner exhibited strong skill in handling a small child, for example, a bond often resulted, which could cause mothers to be loyal to that particular service provider. Mothers valued such referrals from other mothers who had experiential credibility. 
In general, these findings expand the results of prior studies, which have demonstrated the importance of referrals as a means to organise multiple information sources (Bikhchandani et al., 1991) and thus reduce information asymmetry (Levitt, 1983). Referrals also can indicate value and quality (Derbaix \& Vanhamme, 2003) and reveal how and why professional services might be purchased (Dawes et al., 1991). Referrals are particularly important in the health care industry (Fisher \& Anderson, 1990; Gombeski et al., 1990; Murray, 1992; Williams \& Hensel, 1991) because of the high level of information asymmetry between patient and health care professional (Levitt, 1983), the difficulty of judging the service received (Taner \& Antony, 2006) and the patient's reliance on the medical professional to determine a suitable treatment (Mattila \& Wirtz, 2002).

The results of this study highlight the importance of referrals as a source of trusted information about health care providers, from the perspective of mothers. The topics discussed in referrals are within the experience of mothers to judge (i.e., service skills rather than medical qualifications) and are more important than the professional marketing communications of the health care industry or recommendations from medical professionals. Referrals originated either formally, through shared information during a mother's group meeting, or more informally when mothers chatted about their experiences at social events. Some mothers actively sought information to sort through their alternatives; others offered referrals about specific health care providers or organisations because they felt this information would be useful to the recipient.

This research therefore identifies how mothers use referrals, that is, as a primary tool in their information search activities and decision-making processes. Furthermore, this study has shown that the referral source is very important, in that any providers of the information should have some direct experience with the health care provider. The staff who provide the service or supporting services determine mothers' judgements of that service, so staff have a critical role to play. The high-risk decision about medical care prompts mothers to seek our referrals that can reduce their risks and also save them time. 


\section{Managerial implications}

This study offers four practical guidelines for marketers in this industry to implement value-based strategies. First, mothers do not trust marketing and advertising information and recommendations from health care service staff. Instead, they preferred trusted sources of information, such as the word of another mother who has experienced the service. Referrals, from trusted, independent sources, saved a busy mother a potentially long information search and may have helped her to feel more confident about her choice of a health care provider as the best one in order that she may provide the best care for her child.

Therefore, health care marketing, even for highly institutionalised organisations such as private hospitals, must be aimed at reassurance strategies or reinforcement of the service value rather than selling strategies. A hospital's primary goal still may be to increase patient numbers and turnover, but the messages it sends to patients and their families should focus on its commitment to patient care and service value. Such a strategy may work especially well in terms of encouraging word-of-mouth referrals and reinforcing positive perceptions of patient care among mothers.

Second, health care providers must consider staff training, for both medical and nonmedical staff, as a means to promote and develop positive service exchanges with mothers. These patients look to develop a bond with their service provider, whether as patients themselves or as the mothers of patients. The informants in this study talked about the elements of the service provision they were qualified to judge, namely, the bedside manner of the doctors and the friendliness and competence of receptionists.

Third, for many organisations seeking to increase perceptions of value a common practice is to add attributes to existing products, thereby increasing the first value measure of price versus quality. Such a strategy may not work in the health care industry. Mothers are untrusting of the commercial marketing messages from health care providers, thus, attempting to sway opinions with 'cheaper' product bundling strategies or highlighting additional inclusions in existing products may cause concern or confusion. A health care product is likely to be a complex arrangement of attributes (for example, the medical knowledge of the health care professional and their bedside manner, prescribed medications and reception staff) and adding to these 
may serve to confuse or provide concern if the organisation cannot deliver to expectation. Failure to deliver will further reduce perceived value.

Finally, none of the mothers in this study mentioned the physical surroundings of the health care institutions they visited. When this was explored further it seems that a minimum level of physical comfort is taken for granted, as is, some form of distractions to keep children occupied in waiting areas. However, as a means of distinguishing health care organisations from competing offerings the expectations of the mothers in our group show that this is a minor matter compared with the more important manner of staff, professional and administrative.

\section{Limitations and future research}

These findings should be understood within the limitations of this research, including the limited definition of value and the small sample size, selected using a convenience methodology, which limits generalisations of the results. Studying an outcome such as referrals by relying on mothers' memories of past events can be very complex, because of the numerous potential and actual contributory factors involved, such as the seriousness of an illness, the involvement of either the mother or the child, the overall health of the patient, the timing of the events and how much time has passed since those events and the interview.

Finally, the nature of the methodology used is both a limitation and a benefit. Qualitative analysis aims to provide a detailed description rather than causations, and the goal of this research has been to explore the concept of value as it appeared in personal referrals from mothers to other mothers. No attempts to extend these findings to wider populations therefore are made. Despite these limitations and the presentation of the results within the specific boundaries thus prescribed, the research findings offer important insights. All the informants utilised referrals, believed them important and mentioned similar features when they referred (e.g., bedside manner of doctors, friendliness of receptionists). These results not only offer important implications for health care practitioners but also demand further research aimed at understanding the use of referrals by patients across a wider sample. 


\section{REFERENCES}

Batra, R. \& Ahtola, O. T. (1991). 'Measuring the hedonic and utilitarian sources of consumer attitudes.' Educational Psychologist 28(2): 117-148.

Belkin, N.J. (1978). 'Information concepts for information science.' Journal of Documentation 34: 55-85.

Beresford, P. \& Branfield, F. (2006). 'Developing inclusive partnerships: user-defined outcomes, networking and knowledge: a case study.' Health and Social Care in the Community 14(5): 436-444.

Bikhchandani, S.D., Hirshleifer, D., \& Welch, I. (1991). 'A theory of fads, fashions, custom and cultural change as information cascades.' Journal of Political Economy 100: 992-1026.

Bone, P.F. (1992). Determinants of word-of-mouth communications during product consumption. In J. F. Sherry \& B. Sternthal, eds., Advances in Consumer Research Vol. 19 (pp. 579-583). Provo, UT, Association for Consumer Research.

Brady, M. K. \& Cronin, J. J. (2001). 'Some new thoughts on conceptualizing perceived service quality: a hierarchical approach.' Journal of Marketing 65: $34-49$.

Buckland, M.K. (1991). 'Information as thing.' Journal of the American Society for Information Science and Technology 42: 351-360.

Burgoon, J.K., Bonito, J.A., Bengtsson, B., Cederberg, C., Lundeberg, M., \& Allspach, L. (2000). 'Interactivity in human-computer interaction: A study of credibility, understanding, and influence.' Computers in Human Behavior 16: 553-574. 
Coulehan, J. L., Platt, F. W., Egener, B., Frankel, R., Lin, Ch. T., Lown, B., \& Salazar, W. H. (2001). 'Let me see if I have this right...':words that help build empathy.' Annuls of Internal Medicine 135(5): 221-227.

Dawes, P. L., Dowling, G. R. \& Patterson, P. G. (1991). 'Information sources used to select different types of management consultancy services.' Journal Asia Pacific Journal of Management 8(2): 185-199.

de Brentani, U. and Ragot, E. (1996). 'Developing new business-to-business professional services: what factors impact performance?' Industrial Marketing Management 25(6): 517-530.

Derbaix, C. and Vanhamme, J. (2003). 'Inducing word-of-mouth by eliciting surprise — a pilot investigation.' Journal of Economic Psychology 24: 99-116.

Dervin, B. (1990). 'Communication: society's glue, for better, for worse.' Finnish Communication Conference, Tampere, Finland, University of Tampere.

Dick, B. (1990). Convergent Interviewing, Chapel Hill, NC, \& Brisbane: Interchange. Duncan, A. K. \& Breslin, M. A. (2009). 'Innovating health care delivery: the design of health service.' Journal of Business Strategy 30(2/3): 13-20.

Ekrem, C. \& Fazil, K. (2007). Customer Perceived Value: The Development of a Multiple Item Scale in Hospitals, Business Publications.

Ennew, C., Banerjee, A. K., \& Li, D. (2000). 'Managing word of mouth communication: empirical evidence from India.' International Journal of Bank Marketing 18(2): 75-83.

Evans, R. G. (1984). Strained Mercy: The Economics of Canadian Health Care, Toronto, Butterworths.

Fisher, C. M. \& Anderson, C. J. (1990). 'Hospital advertising: does it influence consumers?' Journal of Health Care Marketing 10(4): 40-46. 
Fogg, B.J. (1999). 'Persuasive technologies - now is your chance to decide what they will persuade us to do-and how they'll do it.' Communications of the ACM 42: $26-29$.

Fombrun, C. (1996). Reputation: Realizing Value from Corporate Image, Boston: Harvard Business School Press.

Gombeski, Jr. W. R., Carroll, P. A., \& Lester, J. A. (1990). 'Minicase: influencing decision-making of referring physicians.' Journal of Health Care Marketing 10(4): 56-60.

Gremler, D. D., Gwinner, K. P., \& Brown, S. W. (2001). 'Generating positive wordof-mouth communication through customer-employee relationships.' International Journal of Service Industry Management 12(1): 44-59.

Ham, C. \& Alberti, K. (2002). 'The medical profession, the public and the government.’ British Medical Journal 324: 838-842.

Harris, K. M. (2003). 'How do patients choose physicians? Evidence from a national survey of enrollees in employment-related health plans.' Health Services Research 38(2): 711-732.

Hausman, A. (2004). 'Modeling the patient-physician service encounter: improving patient outcomes.' Journal of the Academy of Marketing Science 32(4): 403 417.

Herzlinger, R. E. (1997). Market-Driven Health Care: Who Wins, Who Loses in the Transformation of America's Largest Service Industry, New York, AddisonWesley.

Heskett, J.L., Jones, T.O., Loveman, G. W., Sasser Jr., W.E., \& Schlesinger, L. A. (1994). 'Putting the service-profit chain to work.' Harvard Business Review Weekly (Mar-Apr): 164-174. 
Hoerger, T.J., Howard, L. (1995), Search behavior and choice of physician in the market for parental care, Medical Care, Vol. 33, No. 4(332-349).

Hogg, G., Laing, A., \& Newholm, T. (2004). 'Talking together: consumer communities and health care.' Advances in Consumer Research 31(67-73).

Holbrook, M. (1994). The Nature of Customer Value, Newbury Park, CA, Sage.

Jadad, A. (1998). 'Promoting partnerships: challenges for the Internet age.' British Medical Journal 319: 761-764.

Janz, N.K. \& Becker, M.B. (1984). 'The health belief model: a decade later.' Health Education Quarterly 11(1): 1-47.

Laing, A. \& Hogg, G. (2002). 'Political exhortation, patient expectation and professional execution: perspectives on consumerization of health care.' British Journal of Management 13(2): 173-188.

Levitt, T. (1983). 'After the sale is over...' Harvard Business Review, 61(5): 87-93.

Lindgreen, A. \& Wynstra, F. (2005). 'Value in business markets: What do we know? Where are we going?' Industrial Marketing Management 34: 735-748.

Lo, Y. N. (2006). Consumers' Expectations of Over-The-Counter (OTC) Medicines: Location of Sale. College of Pharmacy and Nutrition. Saskatoon, University of Saskatchewan. Degree of Master of Science.

Lupton, D., Donaldson, C. and Lloyd, P. (1991). Caveat emptor or blissful ignorance? Patients and the consumerist ethos. Social Science \& Medicine 33(5), 559-568.

Mano, H. \& Oliver, R. L. (1993). 'Assessing the dimensionality and structure of the consumption experience: evaluation, feeling and satisfaction.' Journal of Consumer Research 20, 451-466. 
Mattila, A. \& Wirtz, J. (2001). 'The moderating role of expertise in consumer evaluations of credence goods.' International Quarterly Journal of Marketing 1(4): 281-92.

Murray, K. B. (1992). 'Health care service decision influences: an exploratory investigation of search and nonsearch criteria for professionals and patients.' Journal of Health Care Marketing 12(1): 24-38.

Neuberger, J. (2000). 'The educated patient: new challenges for the medical profession.' Journal of Internal Medicine 247: 6-10.

Nordgren, L. (2009). 'Value creation in health care services - developing service productivity: experience from Sweden.’ International Journal of Public Sector Management 22(2): 114-127.

Quinn, J. B., Doorley, T. L., \& Paquette, P. C. (1990). 'Beyond products: servicesbased strategy.' Harvard Business Review (March-April): 58-68.

Ravald, A. \& Gronroos, C. (1996). 'The value concept and relationship marketing.' European Journal of Marketing 30(2): 19-30.

Richardson, M. L. \& Gurtner, W. H. (1999). 'Contemporary organizational strategies for enhancing value in health care.' International Journal of Health Care Quality Assurance 12(5): 183-189.

Robinson, J. C. (2001). 'The end of managed care.' Journal of the American Medical Association 285(20): 2622-8.

Self, C.S. (1996). 'Credibility.' In M. Salwen and D. Stacks, eds. An Integrated Approach to Communication Theory and Research. Mahwah, NJ: Erlbaum.

Sheth, J.N., Newman, B. I., \& Gross, B. L. (1991). 'Why we buy what we buy: a theory of consumption values.' Journal of Business Research 22(2): 159-170. 
Spiggle, S. (1994). 'Analysis and interpretation of qualitative data in consumer research.' Journal of Consumer Research 21(3): 491-503.

Sweeney, J. \& Soutar, G. (2001). 'Consumer perceived value: the development of a multiple item scale.' Journal of Retailing 77(2): 203-220.

Taner, T. \& Antony, J. (2006). 'Comparing public and private hospital care service quality in Turkey.' Leadership in Health Services 19(2): i-x.

Toweill, D. \& Christopher, M. (2005). 'An evolutionary approach to the architecture of effective healthcare delivery systems.' Journal of Health Organisation and Management 19(2): 130-147.

Treacy, M. \& Wiersema, F. (1993). 'Customer intimacy and other value disciplines.' Harvard Business Review(January-February): 84-93.

Tseng, S. \& Fogg, B.J. (1999). 'Credibility and computing technology.' Communications of the ACM 42: 39-44.

Vargo, S. L. \& Lusch, R. F. (2008). 'Evolving to a new dominant logic for marketing.' Journal of Marketing 68(1): 1-17.

Williams, J. R. \& Hensel, P. J. (1991). 'Changes in physicians' sources of pharmaceutical information: a review and analysis.' Journal of Health Care Marketing 11(3): 46-60.

Zeithaml, V. A. (1988). 'Consumer perceptions of price, quality, and value: a meansend model and synthesis of evidence.' Journal of Marketing, 52(July), $2-22$. 